\title{
Flow characteristics of blade unit of a tridimensional rotational flow sieve tray under concurrent gas-liquid flow
}

\author{
Hongkai Wang ${ }^{1}$, Meng Tang${ }^{1}$, Dewu Wang ${ }^{1}$, Yan Liu ${ }^{1}$, Yishuo Zhang ${ }^{1}$, Ruojin Wang ${ }^{1}$, \\ Baisong $\mathrm{Hu}^{1}$, and Shaofeng Zhang ${ }^{1}$
}

${ }^{1}$ Hebei University of Technology

May 5, 2020

\begin{abstract}
The flow characteristics of the blade unit of a tridimensional rotational flow sieve tray was investigated experimentally in this study. First, the flow patterns are defined under different liquid arrangement methods. They are bilateral film flow, continuous perforated flow, and dispersion-mixing flow in overflow distribution and film and jet flow and jet and mixed flow in spray distribution. Second, the time and frequency domain analysis of the differential pressure pulsation signal in the blade unit is carried out. The influence of perforation and mixing intensity on the flow pattern transition is clarified. Third, the rotational flow ratio of the gas-liquid phase is measured. The influence of the operating conditions on the distribution of the rotational and perforated flow for the gas-liquid phase is investigated. Finally, a prediction model for the rotational flow ratio is proposed. The prediction results agree well with the experimental data.
\end{abstract}
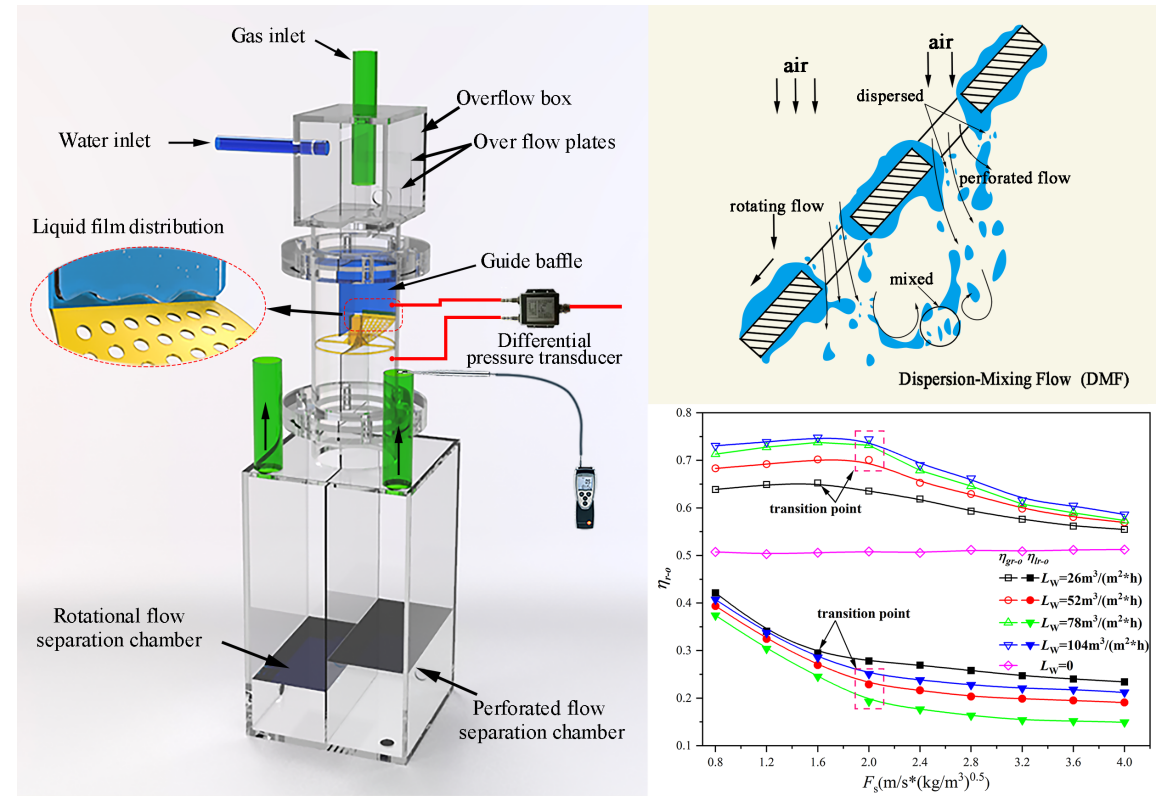

\section{Hosted file}

manuscript.pdf available at https://authorea.com/users/292457/articles/420303-flowcharacteristics-of-blade-unit-of-a-tridimensional-rotational-flow-sieve-tray-under- 
concurrent-gas-liquid-flow 